\title{
LAPROSCOPIC ASSISTED SWENSON PULL-THROUGH FOR CLASSIC HIRSCHSPRUNG'S DISEASE WITH SIGMOID COLOSTOMY: A SINGLE CENTER EXPERIENCE
}

\author{
Sajjad Ali ${ }^{1 \otimes}$, Inayat ur Rehman', Tariq Waheed', Mohammad Imran', \\ Farooq Abdullah', Hazrat Amin'
}

\begin{abstract}
OBJECTIVE: To share our experience of laparoscopic assisted Swenson pullthrough for classic Hirschsprung's disease (HD) with sigmoid colostomy.

METHODS: Thirty-one patients with HD and sigmoid colostomy operated in Pediatric Surgery department, Khyber Teaching Hospital, Peshawar, Pakistan, between June 2014 and June 2018 were included. Patients with long segment HD, and those operated elsewhere were excluded from the study. Demographic characteristics, intraoperative findings and post operative course were retrieved from files. Post-operative outcome at $3^{\text {rd }}, 6^{\text {th }}$ and $12^{\text {th }}$ month follow ups were taken from follow up charts.
\end{abstract}

RESULTS: Mean age and weight of patients were 13.23 \pm 1.76 months and $7.89 \pm 1.42 \mathrm{~kg}$, respectively. Male to female ratio was $6.75: 1$. Mean operative time, duration of urinary catheterization and hospital stay were $171.87 \pm 15.76 \mathrm{~min}$, $0.79 \pm 1.02$ days and $5.91 \pm 1.01$ days, respectively. After surgery, stool consistency was liquid in $12(61.29 \%)$ and loose in $12(38.7 \%)$ patients. However, stool frequency was $>3$ times/day in $10(32.25 \%)$ cases, $2-3$ times/day in $18(58.06 \%)$ patients and 0 - I time/day in $3(9.67 \%)$ patients. Surgical site infection and perianal excoriation were seen in $2(6.45 \%)$ and II (35.48\%) patients, respectively. Progressive improvement in stool consistency and frequency was noticed at $12^{\text {th }}$ month follow up. Perianal excoriation was seen II (35.48\%) patients at $3^{\text {rd }}$ month, $6(19.35 \%)$ patients at $6^{\text {th }}$ and I $(3.22 \%)$ patient at $12^{\text {th }}$ month follow up

CONCLUSION: Laparoscopic assisted Swenson pull-through is a good treatment option for patient with recto-sigmoid HD and bears a predictable and acceptable stooling pattern, optimum hospital stay and minimal complications.

KEY WORDS: Hirschsprung's Disease (MeSH); Colon, Sigmoid (MeSH); Colostomy (MeSH); Laparoscopic assisted pull-through surgery (Non-MeSH); Swenson pull-through (Non-MeSH)

THIS ARTICLE MAY BE CITED AS: Ali S, Rehman IU, Waheed T, Imran M, Abdullah F, Amin H. Laproscopic assisted swenson pull-through for classic Hirschsprung's disease with sigmoid colostomy: A single center experience. Khyber Med Univ J 2020; I2(4): 268-7I. DOI: 10.35845/kmuj.2020.20302.

\section{INTRODUCTION}

The history of Hirschsprung's disease (HD) is traced back to Frederik Ruysch, a Dutch anatomist, who reported it in 1691.' However, the disease is named after a pathologist, Harald Hirschsprung, who first presented the histopathologic images of this disease in 1887 in two infants. ${ }^{2}$ The literature reveals the incidence of HD as I in 5000 live births. ${ }^{3,4}$ It is seen four times more commonly in males as compared to females and is predominant in white ethnicity. ${ }^{5}$ The condition has a significant association with Down syndrome with an incidence of 9\%. ${ }^{6}$

Hirschsprung's disease is a hereditary condition of large gut and RET protooncogene is a predominant genetic culprit. ${ }^{7}$ It is congenital aganglionosis of colon in an ascending pattern involving rectum and in all cases and may be extensive in a proximal fashion up the large gut or less commonly small gut too. The hallmark presentation of chronic
I. Department of Pediatric Surgery, Medical Teaching Institute Khyber Teaching Hospital, Peshawar, Pakistan. Email区: sajjadbuneri@gmail.com Contact \#: +92-332-9941534

$\begin{array}{ll}\text { Date Submitted: } & \text { May 06, 2020 } \\ \text { Date Revised: } & \text { November 09, 2020 } \\ \text { Date Accepted: } & \text { November I5, 2020 }\end{array}$

constipation is due to decreased gut motality secondary to congenital absence of ganglion cells in the involved portion of gut. The disease mostly presents in infancy but patient can report at any age usually before of 10 years. ${ }^{8}$ A barium enema can give a preliminary diagnosis of Hirschsprung's disease but deficiency/absence of ganglionic cells on rectal biopsy is a confirmatory. ${ }^{9,10}$ Our study included only those patients which had classic recto sigmoid HD.

Treatment of the condition is surgical and involve resection of proven aganglionic colonic segment and anastomosing the remaining. Soave, Boley, Duhamel and Swenson are different surgical procedures." In Swenson pull-through, the aganglionic segment of colon is resected and ganglionic portion is pulled through and anastomosed $1.5 \mathrm{~cm}$ above the dentate line. Orvar Swenson devised this procedure in 1940s, so is named after him. ${ }^{12,13}$ With the advent of minimal invasive surgery, pull-through procedures are performed laproscopically and even with robot. As there is no local study available on laparoscopic assisted pullthrough surgery, we planned to share our experience of laparoscopic assisted Swenson pull-through in patients with classic Hirschsprung's disease involving the rectosigmoid gut only. Since we do not have the facility of frozen section biopsy, prior sigmoid colostomy is a pre-requisite for laparoscopy assisted Swenson pullthrough in our set up.

\section{METHODS}

This retrospective study was conducted at 
TABLE I: OPERATIVE OUTCOME OF LAPAROSCOPIC ASSISTED PULL-THROUGH SURGERIES DURING HOSPITAL STAY $(n=3 \mid)$

\begin{tabular}{|l|l|c|}
\hline Operative outcomes & No. of patients (\%) \\
\hline \multirow{3}{*}{ Stool consistency } & Liquid & $19(61.29 \%)$ \\
\cline { 2 - 3 } & Loose & $12(38.70 \%)$ \\
\cline { 2 - 3 } & Formed & $0(0.0 \%)$ \\
\hline \multirow{3}{*}{ Stool frequency } & 0 to I times/day & $3(9.67 \%)$ \\
\cline { 2 - 3 } & 2 to 3 times/day & $18(58.06 \%)$ \\
\cline { 2 - 3 } & More than 3 times/day & $10(32.25 \%)$ \\
\hline Surgical site infection & $2(6.45 \%)$ \\
\hline Perianal excoriation & $11(35.48 \%)$ \\
\hline Enterocolitis & $0(0.0 \%)$ \\
\hline Adhesive obstruction & $0(0.0 \%)$ \\
\hline Mortality & $0(0.0 \%)$ \\
\hline
\end{tabular}

TABLE II: FOLLOW UP DATA AT $3^{\text {RD }}, 6^{\text {TH }}$ AND $12^{\text {TH }}$ MONTH OF LAPAROSCOPIC ASSISTED PULL-THROUGH SURGERIES $(n=3 \mid)$

\begin{tabular}{|l|l|c|c|c|}
\hline \multicolumn{2}{|c|}{ Parameters } & At $^{\text {rd }}$ month & At $^{\text {th }}$ month & At I2 $^{\text {th }}$ month \\
\cline { 2 - 5 } & $\mathbf{n}(\%)$ & $\mathbf{n}(\%)$ & $\mathbf{n}(\%)$ \\
\hline \multirow{2}{*}{$\begin{array}{l}\text { Stool } \\
\text { consistency }\end{array}$} & Liquid & $0(0.0 \%)$ & $0(0.0 \%)$ & $0(0.0 \%)$ \\
\cline { 2 - 5 } & Loose & $18(58.06 \%)$ & $3(9.67 \%)$ & $0(0.0 \%)$ \\
\cline { 2 - 5 } & Formed & $13(41.93 \%)$ & $28(90.32 \%)$ & $31(100.0 \%)$ \\
\hline \multirow{2}{*}{$\begin{array}{l}\text { Stool } \\
\text { frequency }\end{array}$} & 0 to I & $6(19.35 \%)$ & $15(48.38 \%)$ & $24(77.41 \%)$ \\
\cline { 2 - 5 } & 2 to 3 & $17(54.83 \%)$ & $10(32.25 \%)$ & $7(22.58 \%)$ \\
\cline { 2 - 5 } & More than 3 & $8(25.80 \%)$ & $6(19.35 \%)$ & $0(0.0 \%)$ \\
\hline Perineal excoriation & $11(35.48 \%)$ & $6(19.35 \%)$ & $1(3.22 \%)$ \\
\hline Enterocolitis & $0(0.0 \%)$ & $0(0.0 \%)$ & $0(0.0 \%)$ \\
\hline \multicolumn{2}{|l|}{ Adhesive obstruction } & $0(0.0 \%)$ & $2(6.45 \%)$ & $0(0.0 \%)$ \\
\hline \multicolumn{2}{|l|}{ Mortality } & $0(0.0 \%)$ & $0(0.0 \%)$ & $0(0.0 \%)$ \\
\hline
\end{tabular}

Pediatric Surgery department, Khyber Teaching Hospital, Peshawar, Pakistan. Study was approved by institutional review and ethical board. Thirty-one patients with confirmed Hirschsprung's disease (HD) on histopathology and sigmoid colostomy operated in between June 2014 and June 2018 were included in the study. HD patients with acute enterocolitis, massively dilated rectum (delayed referral) and long segment (transition zone above the sigmoid) were excluded from the study. All patients had primary decompressing colostomy before laparoscopic assisted pull-through procedure was offered.

After formal gut preparation and intravenous antibiotics at the induction of anesthesia, Indwelling catheterization and nasogastric intubation were done. Trendlenberg was our preferred position. Umbilical port of $3 \mathrm{~mm}$ was always our first port for pnumopertonium while $2^{\text {nd }}$ and $3^{\text {rd }} 3 \mathrm{~mm}$ ports were placed under laparoscopic guidance in right and left flank. Rectal dissection was done distally till the peritoneal reflection and colonic mobilization upto splenic flexure proximally by Ligasure (Figure I). Rest of the pull-through was done by transanal approach (Figure 2). Aganglionic portion was resected and ganglionic portion was anastomed above the dentate line.The nasogastric tube was usually removed on the $2^{\text {nd }}$ postoperative day and oral feeding started.

Demographic features, history and physical examination were noted. Intraoperative findings of patients undergone laparoscopic assisted pullthrough procedure were recorded. The data was entered into SPSS version 20, computer program and analyzed accordingly. Study variables were analysed by simple descriptive statistics. Mean and standard deviation were calculated for numerical variables (age). Frequency and percentage were calculated for gender, intraoperative findings and post-operative outcome of laparoscopic assisted pullthrough procedure at $3^{\text {rd }}, 6^{\text {th }}$ and $12^{\text {th }}$ month follow ups

\section{RESULTS}

Out of 3 I patients, 27 (87.09\%) were males and $4(12.90 \%)$ were females with male to female ratio of $6.75: 1$. Patients ranged in age from 9-18 months and mean age of patients was $13.23 \pm 1.76$ months. Mean weight of babies was $7.89 \pm 1.42 \mathrm{~kg}$. There were no case of any other associated congenital abnormality. There was no past history of surgery other than sigmoid colostomy in all patients.

All cases were successfully completed laparoscopically and none of the cases was converted to open surgery. Mean operative time of laparoscopic surgery was $171.87 \pm 15.76$ minutes. Mean duration of urinary catheterization was $0.79 \pm 1.02$ days. Mean hospital stay was $5.9 \mathrm{I} \pm \mathrm{I} .0 \mathrm{I}$ days. Surgical site infection was noted in $2(6.45 \%)$ cases. We did not encounter any mortality. The Operative outcome of laparoscopic assisted pullthrough surgeries during hospital stay and Follow up at $3^{\text {rd }}, 6^{\text {th }}$ and $12^{\text {th }}$ month of laparoscopic assisted pull-through surgeries are shown in Table I and II repectively.

\section{DISCUSSION}

Regarding our findings, the mean age of patients was 13.23 \pm 1.76 months (Range: 9-18 months). In a study by Georgeson KE, et al. the age of patients ranged from 3 days to 966 days. ${ }^{14}$ In another study by Yan J, et al. the mean age of patients who underwent laparoscopic surgery for Hirshsprung disease was $6.2 \pm 2.07$ months. ${ }^{15}$ Similarly in work by Singh $S$, et al. the mean age of patients was $6.0 \pm 0.23$ months. ${ }^{16}$ Male dominance was observed in our study i.e. $87.09 \%$ male and $12.90 \%$ females. Males were also predominant in a study by Yan J, et al. i.e. $72.23 \%$ male. ${ }^{15}$ As far concerned weight, the mean recorded wieght was $7.89 \pm 1.42 \mathrm{~kg}$ in our study. Similarly, in a study by Yan J, et al. the mean weight of patients undergoing laparoscopic surgery for Hirshsprung disease was $8.1 \pm 2.45 \mathrm{~kg}{ }^{15}$ Study by Singh $\mathrm{S}$, et al. found male to female ratio of 24:1. ${ }^{16}$ We did not come come across any other congenital abnormality $(0.0 \%)$ in association to the condition under consideration. However, in a study by Singh S, et al. $4.0 \%$ subjects exhibited features of Down syndrome. ${ }^{16}$

The mean recorded operative time of laparoscopic assisted pull-through was $171.87 \pm 15.76$ min in our study. In a study 


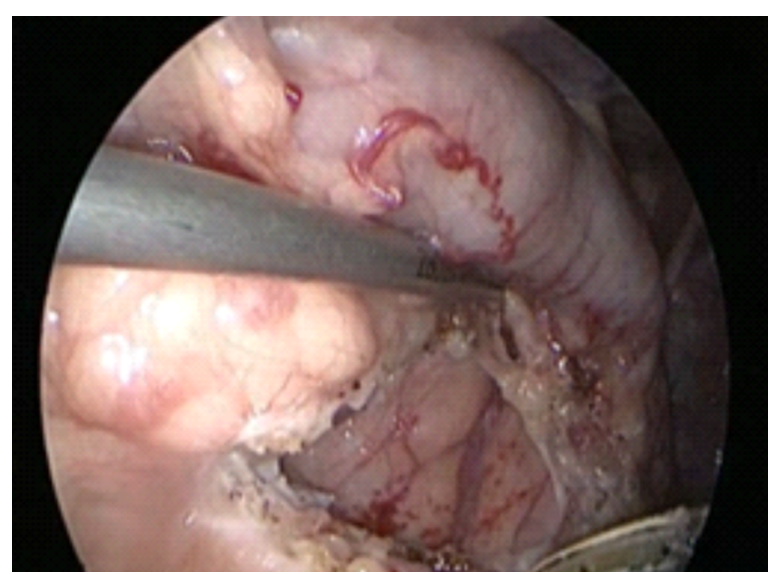

Figure I: Laparoscopic mobilization

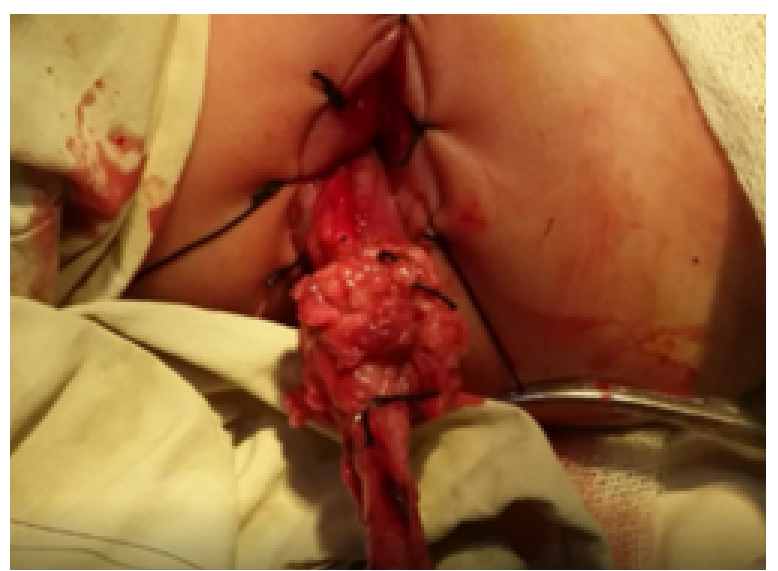

Figure 2: Transanal pull-through by Georgeson KE, et al. the mean duration of surgery was 2.5 hours. ${ }^{14}$ Similarly, in a study by Yan J, et al. this figure was 175.5 \pm 20.7 min. ${ }^{15}$ Similarly Singh S, et al. showed a mean operative time of $80 \pm 0.30$ min. ${ }^{16}$ Not a single laparoscopic pull thorough surgery was converted to open surgery $(0.0 \%)$ in our study. However, in a study by Georgeson KE, et al. conversion to open surgery was reported in $2.5 \%$ pateints. ${ }^{14}$ Similar to our study, there was no convsersion of laparoscopic assisted surgery to open surgery in any patient in a study by Singh S, et al. $^{16}$

We recorded a mean duration of urinary catheterization as $0.79 \pm 1.02$ days. Post operatively during hospital stay, the consistency of stool was liquid 19 (61.29\%) patients while in other 12 $(38.70 \%)$ patients the consistency was stool was found loose in our study. However, formed stool consistency was not observed in any patient i.e. $0.0 \%$. In a study by Georgeson KE, et al. 7.5\% patients develped diarrhea after surgery. ${ }^{14}$ We graded stooling frequency as time per day and post operatively we recorded a frequency of 0 - I times/day in 3 (19.35\%) cases, $2-3$ times/day in 18 (54.83\%) and more than 3 times day in 10 (32.25\%) patients. Surgical site infection was recorded in $2(6.45 \%)$ patients in our study. However, surgical site infection was not seen in any patient $(0.0 \%)$ after laparoscopic surgery for Hirshsprung disease in a work by Yan J, et al. ${ }^{15}$ In our study, II (35.48\%) patients developed perianal skin excoriation in post operative hospital stay. Mean hospital stay of patients in our study was 5.91 \pm 1.01 days. In a study by Georgeson KE, et al. the average hospital stay was 3.7 days. ${ }^{14}$ Similar to our study, the mean operative time of laparoscopic surgery for Hirshsprung disease was $6.2 \pm 1.5$ days in a study by Yan J, et al. ${ }^{15}$ Another study by Singh S, et al. showed this duration as $6 \pm 0.21$ days. ${ }^{16}$

The follow up data of patients at 3,6 and 12 months was retrieved (Table II). Consistency of stool at $3^{\text {rd }}$ month follow up was loose in 18 (58.06\%) patients. However, most of these patients showed improved consistency towards formed stools at $6^{\text {th }}$ and $12^{\text {th }}$ month follow up i.e. 18 $(90.32 \%)$ and 31 (100.0\%) patients, respectively in our study. The stool frequency was high in majority of patients at $3^{\text {rd }}$ month follow up but at $6^{\text {th }}$ and $12^{\text {th }}$ month follow ups, was improved was improved (decreased) in most of these patients at $6^{\text {th }}$ and $12^{\text {th }}$ month. Perianal skin excoriation was seen in II (35.48\%) patients at $3^{\text {rd }}$ month follow up, 6 (19.35\%) patients at $6^{\text {th }}$ month follow up and $\mathrm{I}(3.22 \%)$ patients at $12^{\text {th }}$ month follow up in our study. In a study by Yan J, et al. the diaper rash was seen in $5.56 \%$ patients post laparoscopic surgery for Hirshsprung disease at 6-12 months follow up. ${ }^{15}$ Enterocolitis was not observed in any patient at all follow ups in our study, however, adhesive intestinal obstruction was diagnosed in 2 (6.45\%) patients at $6^{\text {th }}$ month follow up which was managed conservatively. In a study by Georgeson KE, et al. enterocolitis was reported in $7.5 \%$ pateints. ${ }^{14}$ However, enterocolitis and intestinal obstruction were not observed in any patient after laparoscopic surgery for Hirshsprung disease in a study by Yan J, et al. ${ }^{15}$

We did not encounter any mortality $(0.0 \%)$ throughout our study. Similarly, in a study by Georgeson KE, et al. no mortality was observed. ${ }^{14}$ However, mortality $(4.0 \%)$ was observed in a study by Singh $S$, et al. ${ }^{\prime}$

\section{LIMITATIONS}

This study has certain limitations as it is a single center study with limited patients. A large series of patients is required to thoroughly evaluate the results of the modality discussed.

\section{CONCLUSION}

Hetrogenity in results of different modalities of treatment like Swenson, Soave and Duhamel pull-through procedures is preventing identification of a gold standard. Laproscopic assisted Swenson pull-through is a recent advancement in minimal invasive approach for the treatment of HD. Our experience with this technique shows that it can be a good treatment option for patients with HD. However the procedure needs to be compared with its open alternative and other procedures for functional outcome and complications prior to recommending it.

\section{REFERENCES}

I. Leenders E, Sieber WK. Congenital megacolon observation by Frederick Ruysch-1691. J Pediatr Surg 1970;5 (I): I-3. DOI: 10.10I6/0022-3468(70) 905I2-9.

2. Chatelain D, Manaouil C, Marc B, Ricard J, Brevet M, Montpellier D, et al. Adult Hirschsprung's disease diagnosed during forensic autopsy. J Forensic Sci 2006; 5 I (5): I I60-3. DOI: |0. I | | |/j. |556-4029.2006.00235.x. 
3. Hussain S, Mazhar A, Siddiqui A. Transanal endorectal pull-through: an eff ective alternative to staged management of Hirschsprung's disease. Semin Pediatr Surg 2010 May;19(2):96-106. DOI: 10.1053/ j.sempedsurg.2009.11.016.

4. Askarpour SH, Samimi K. Epidemiologic and clinical specifications of patients with Hirschsprung's disease in Khouzestan province Iran. J Surg Pak (Int). 2008; 13:75-8.

5. Karim A, Akter M, Aziz TT, Hoque M, Chowdhury TK, Imam MS, et al. Epidemiological characteristics of Hirschsprung's disease (HSCR): Results of a case series of fifty patients from Bangladesh. J Pediatr Surg 2018;53(10):1955-9. DOI: 10.1016/ j.jpedsurg.2017.12.029.

6. Bradnock TJ, Knight M, Kenny S, Nair M, Walker GM. Hirschsprung's disease in the UK and Ireland: incidence and anomalies. Arch Dis Child 2017;102(8):722-7. DOI: |0.1|36/archdischild-20|6-3| |872.

7. Tomuschat C, Puri P. RET gene is a major risk factor for Hirschsprung's disease: a meta-analysis. Pediatr Surg Int 20I5;3I(8):70I-I0. DOI: I0.1007

$$
\text { /s00383-0I5-373I-y. }
$$

8. Tam PK. Hirschsprung's disease: a bridge for science and surgery. J Pediatr Surg 2016 Jan I;5I(I):I8-22. DOI: $10.1016 / j$.jpedsurg. 2015 . I0.021.

9. Wong CW, Lau CT, Chung PH, Lam WM, Wong KK, Tam PK. The value of the 24-h delayed abdominal radiograph of barium enema in the diagnosis of Hirschsprung's disease. Pediatr Surg Int 20I5;3I(I):II-5. DOI: $10.1007 / \mathrm{s} 00383-0 \mid 4-3632-5$.

10. Muise ED, Cowles RA. Rectal biopsy for Hirschsprung's disease: a review of techniques, pathology, and complications. World J Pediatr 2016; I2(2):135-4I. DOI: 10.1007/s |25|9-0|5-0068-5.

II. Gupta DK, Khanna K, Sharma S. Experience with the redo pullthrough for hirschsprung's disease. J Indian Assoc Pediatr Surg 2019; 24(I):45-5I. DOI: 10.4I03/jiaps. JIAPS_52_18.

I2. Bai Y, Chen H, Hao J, Huang Y, Wang $W$. Long-term outcome and quality of life after the Swenson procedure for Hirschsprung's disease. J Pediatr Surg 2002;37(4):639-42. DOI: 10. 1053/jpsu.2002.31625.

13. Al-Baghdady AA, El-Shafei EA, EIAsmar KM. One-stage transanal Swenson procedure for rectosigmoid Hirschsprung's disease in infants and children. Ann Pediatr Surg 2016; 12(3): I04-8. DOI: 10.1097/0I.XPS. 0000482859.77300 .04 .

14. Georgeson KE, Cohen RD, Hebra A, Jona JZ, Powell DM, Rothenberg SS, et al. Primary laparoscopic-assisted endorectal colon pull-through for Hirschsprung's disease: a new gold standard. Ann Surg 1999;229(5):67882. DOI: $10.1097 / 00000658-19990$ 5000-000I0.

15. Yan J, Li S, Chang Y, Wang J, Li A. Comparison of transcolostomy singleincision laparoscopic and open procedures in secondary operations for hirschsprung's disease. Biomed Res 2017;28(8):3527-31.

16. Singh S, Wakhlu A, Ahmad I, Srivastava NK. The laparoscopic assisted Duhamel pull through procedure for Hirschsprung's disease: our technique and short term results. J Pediatr Neonatal Care 2017;7(2):0028I. DOI: 10.15406/jpnc.2017.07.0028I.

\section{AUTHORS' CONTRIBUTIONS}

Following authors have made substantial contributions to the manuscript as under:

SA: Conception \& study design, acquisition of data, drafting the manuscript, critical review, approval of final version to be published

IUR: Acquisition of data, drafting the manuscript, approval of final version to be published

TW \& MI: Analysis and interpretation of data, drafting the manuscript, approval of final version to be published

FA: Acquisition, analysis and interpretation of data, critical review, approval of final version to be published

HA: Study design, acquisition, analysis and interpretation of data, drafting the manuscript, approval of final version to be published

Authors agree to be accountable for all aspects of the work in ensuring that questions related to the accuracy or integrity of any part of the work are appropriately investigated and resolved.

\begin{tabular}{|c|}
\hline CONFLICT OF INTEREST \\
Authors declared no conflict of interest \\
GRANT SUPPORT AND FINANCIAL DISCLOSURE \\
NIL
\end{tabular}

\section{DATA SHARING STATEMENT}

The data that support the findings of this study are available from the corresponding author upon reasonable request.

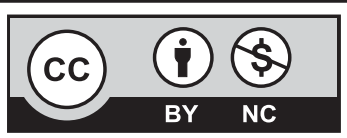

This is an Open Access article distributed under the terms of the Creative Commons Attribution-Non Commercial 2.0 Generic License. 